\title{
Multi-Domain Model for Electric Traction Drives Using Bond Graphs
}

\author{
Luis I. Silva ${ }^{\dagger}$, Pablo M. de la Barrera*, Cristian H. De Angelo*, Facundo Aguilera*, and Guillermo O. García* \\ †* Grupo de Electrónica Aplicada, Facultad de Ingeniería, Universidad Nacional de Río Cuarto, Río Cuarto, Argentina
}

\begin{abstract}
In this work the Multi-Domain model of an electric vehicle is developed. The electric domain model consists on the traction drive and allows including faults associated with stator winding. The thermal model is based on a spatial discretization. It receives the power dissipated in the electric domain, it interacts with the environment and provides the temperature distribution in the induction motor. The mechanical model is a half vehicle model. Given that all models are obtained using the same approach (Bond Graph) their integration becomes straightforward. This complete model allows simulating the whole system dynamics and the analysis of electrical/mechanical/thermal interaction. First, experimental results are aimed to validate the proposed model. Then, simulation results illustrate the interaction between the different domains and highlight the capability of including faults.
\end{abstract}

Key Words: Bond Graph, Electric Vehicle, Induction Motor, Multi-Domain Modeling, Simulation

\section{INTRODUCTION}

Nowadays Electric Vehicles (EV) and/or Hybrid Electric Vehicles (HEV) are studied as possible solution to improve fuel economy and reduce vehicle emissions.

In recent years modeling and simulation became a helpful tool during the design stage of EVs [1]. However, despite having a well detailed model of the traction drive, it may occur that after the prototype construction it works outside design conditions. It happens because the mechanical load is not properly modeled or because the negative impact produced by overheating on the motor life is not considered [2]. Therefore the model needs to be expanded to incorporate those effects.

Based on these reasons, the development of Multi-Domain models that integrate electric, thermal and mechanical behavior becomes a helpful tool to facilitate the EV modeling. Using these models it is feasible to do the thermal analysis together with the evaluation of: fault detection systems, performance of different controllers, configurations, topologies and materials applied on the motor. This complete analysis can be carried out even prior to the actual construction of the prototype.

The traditional approach used to create a Multi-Domain model that incorporates all these phenomena consists on writing down the complete set of equations related with each domain. Then it is necessary to explicit their interaction and to model the parameters variation depending on the evolution of other domains. Given that this procedure is time consuming and error prone, several simplifications are commonly

\footnotetext{
Manuscript received Jan. 1, 2011; revised May 16, 2011

Recommended for publication by Guest Associate Editor Byoung-Kuk Lee.

$\dagger$ Corresponding Author: 1silva@ieee.org

Tel: +54-358-4676255, Universidad Nacional de Río Cuarto

* Grupo de Electrónica Aplicada, Facultad de Ingeniería, Universidad Nacional de Río Cuarto, Argentina
}

performed thus loosing accuracy. In [3] the electric and the mechanical models of a high-speed train were integrated.

To facilitate the modeling task of Multi-Domain physical systems, special software were developed. They incorporate sub-systems that consider other domains and their interaction but they are less flexible and require specific knowledge of the software. In [4] Comsol Multy-Physics is used to integrate the magnetic/electrical/thermal models of a coated conductor in presence of critical currents whereas PSIM proved to be a valid software tool to model and simulate together the electrical, mechanical and thermal behavior of EV and HEV [5].

The core of this work is the development of a Multi-Domain model of the traction drive of an EV. For the case of study, Induction Motors (IM) are used to drive the vehicle. The mechanical behavior of the vehicle needs to be incorporated as the motor load in order to determine the working conditions more accurately. When the "Motor - Load" system is working, the own thermal characteristics plus the environment interaction determine the working temperature.

In this work the electric sub-model that considers Iron Losses (IL) is firstly obtained. It contains a special feature: the stator resistances are in the $a b c$ frame. It allows a temperature distribution analysis of the stator and the inclusion of faults associated to stator winding. On the other hand, the rest of the electric dynamics is modeled in the $d q 0$ frame. The electric variables expressed in this frame are needed to implement the Field Oriented Control (FOC) [6]. Secondly, the thermal model that takes into account the spatial distribution of the stator winding is constructed. Finally, the longitudinal dynamical model of the EV is presented. The last step consists on the integration of these sub-models into a complete dynamical MultiDomain model that is used to perform different simulations. 
The rest of the paper is organized as follows: In section II the advantages of using Multi-Domain models are discussed. Sections III, IV and V are devoted to describe and model the electric, thermal and mechanical behavior, respectively. Along section VI the integration of the sub-models is carried out. In Section VII simulation and experimental results of the complete system performance are provided in order to validate the proposed model and to illustrate the interaction between domains. In section VIII conclusions about the benefits of the model are provided together with future works.

\section{Multi-Domain Modeling}

In this section, we firstly present some of the challenges associated with EV design and explain the motivation for using Multi-Domain modeling as a viable approach to fulfill these challenges. Then the proposed procedure to obtain the complete Multi-Domain model is outlined.

\section{A. Motivation}

The mathematical complexity of an EV design problem is reflected in the large number of variables involved and the complex nonlinear relationships between them. Thus, defining the right set of requirements to meet the vehicle performance and functionality goals becomes tedious and error-prone with analytical solutions.

The design stage requires understanding the behavior of the various components involved and their complex interactions. Moreover, in order to develop the final model, some intermediate stages are needed. This is because initially each subsystem is represented by a simple model and, as the design progresses, they are replaced with a more detailed model. For this reason, the modeling procedure should be object oriented and performed in a modular way.

The widespread method to incorporate these phenomena is based on writing down the complete set of equations related with each domain. This procedure is not object and each modification implies modifying the complete set of equations. It is time consuming and error prone, thus several simplifications are performed reducing accuracy.

Another approach is to use different modeling techniques for each domain, using sometimes a specific designed tool for each simulation. Using this method it is difficult to evaluate the interactions between domains. On the other hand, software specially developed to model EVs may incorporate sub-systems that consider other domains and their interaction but they are less flexible and require specific knowledge of the software.

The main motivation to model each component of the EV system with the same modeling approach is that these components are designed by specialists from electrical, mechanical and thermal domain among others. When the designs are performed with the same modeling approach specialists are able to effectively communicate without ambiguity. So, in order to analyze the behavior of the traction drive of an $\mathrm{EV}$, it is necessary to construct a Multi-Domain model that represents simultaneously the electric, thermal and mechanical domains.

In this paper a modeling approach able to address the aforementioned challenges is discussed.

\section{B. Proposed Procedure}

For the purpose of this paper, it is necessary to use a formalism capable to model the behavior of each domain involved. There are two mainly used object oriented modeling approaches for Multi-Domain systems, Kirchhoffians Networks [7] and Bond Graphs (BG) [8], [9]. Although both approaches are similar [10], in this work a BG model is developed, given the direct correspondence between the $\mathrm{BG}$ representation and the physical topology [11].

The proposed procedure consists on the development of the electric, thermal and mechanical BG sub-models separately. First the interactions of each sub-model with the others are considered as input/output signals and are left unconnected. Then the complete Multi-Domain model is achieved by including the interactions between domains (i.e. these signals are connected according to the corresponding interaction).

This simple procedure allows focusing on each domain during the design process but the easy integration with other domains gives a rapid idea of the overall performance. This feature permits to analyze the behavior of each component when it operates together and simultaneously with components of other domains.

Next, the developments of these models are presented together with their integration into the complete model.

\section{IM ELECTRIC MODEL}

The IM model in $d q 0$ variables [12] is widely used to tune digital controllers used in FOC. With few modifications it is possible to consider other phenomena such as: IL and/or additional losses ("stray load losses") [13]; faults concerning stator winding short-circuits [14] and broken rotor bars [15].

In [16] a model in $d q 0$ variables that considers IL is presented. Based on this model it is possible to derive control schemes to avoid errors in the estimation of flux and torque (needed in the FOC) when IL appear [17]-[20].

In this section the dynamic model of the IM in $d q 0$ variables considering IL is presented. The stator IL is represented by an equivalent resistance $\left(R_{F e}\right)$ in parallel with the magnetizing branch. Fig. 1 shows the equivalent circuit in $d q 0$ variables. The model does not consider variables in the 0 axis because it is balanced and the neutral conductor is not connected.

\section{A. Electrical Model Considering Iron Losses}

Based on Fig. 1, voltage and flux are deduced:

$$
\begin{aligned}
v_{d s} & =-\omega \lambda_{q s 1}+\dot{\lambda}_{d s 1}+R_{s} i_{d s 1}+R_{F e}\left(i_{d s 1}-i_{d s 2}\right) \\
v_{q s} & =\omega \lambda_{d s 1}+\dot{\lambda}_{q s 1}+R_{s} i_{q s 1}+R_{F e}\left(i_{q s 1}-i_{q s 2}\right) \\
0 & =-\omega \lambda_{q m}+\dot{\lambda}_{d m}+R_{F e}\left(i_{d s 2}-i_{d s 1}\right) \\
0 & =\omega \lambda_{d m}+\dot{\lambda}_{q m}+R_{F e}\left(i_{q s 2}-i_{q s 1}\right) \\
v_{d r} & =\left(\omega-\omega_{r}\right)\left(\lambda_{q r 1}+\lambda_{q m}\right)+\left(\dot{\lambda}_{d r 1}+\dot{\lambda}_{d m}\right)+R_{r} i_{d r} \\
v_{q r} & =\left(\omega-\omega_{r}\right)\left(\lambda_{d r 1}+\lambda_{d m}\right)+\left(\dot{\lambda}_{q r 1}+\dot{\lambda}_{q m}\right)+R_{r} i_{q r}
\end{aligned}
$$

where the currents, fluxes and voltages are represented by $i, \lambda$ and $v$, respectively; subscripts $q$ and $d$ indicate variables referred to those axes, and $s, r$ and $m$ refer to stator, rotor and air-gap, respectively. 


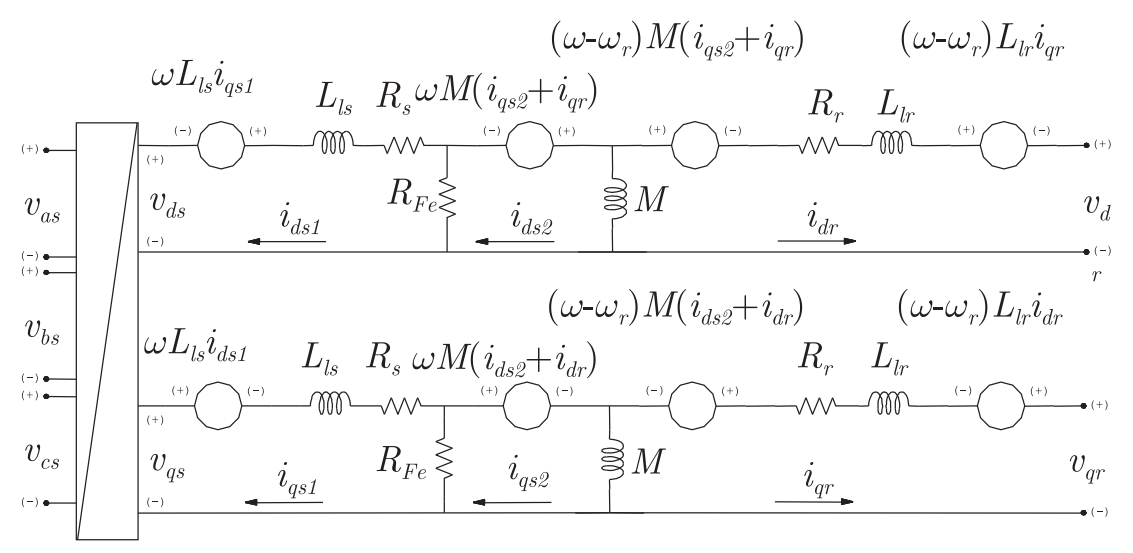

Fig. 1. IM equivalent circuit in $d q 0$ variables.

The stator, rotor and air-gap fluxes equations are:

$$
\begin{aligned}
\lambda_{d s 1} & =L_{l s} i_{d s 1} \\
\lambda_{q s 1} & =L_{l s} i_{q s 1} \\
\lambda_{d m} & =M\left(i_{d s 2}+i_{d r}\right) \\
\lambda_{q m} & =M\left(i_{q s 2}+i_{q r}\right) \\
\lambda_{d r 1} & =L_{l r} i_{d r} \\
\lambda_{q r 1} & =L_{l r} i_{q r}
\end{aligned}
$$

Applying power invariant transformation, the electromagnetic torque can be expressed in $d q 0$ variables as [12]:

$$
T_{e}=\left(\frac{P}{2}\right) M\left(i_{q s 2} i_{d r}-i_{d s 2} i_{q r}\right)
$$

where $P$ is the number of poles. From (2) and (3) it can be obtained an alternative expression:

$$
T_{e}=\left(\frac{P}{2}\right)\left(i_{d r} \lambda_{q m}-i_{q r} \lambda_{d m}\right)
$$

\section{B. Electric Model in Bond Graph}

To design and test different control strategies it is necessary to have an accurate electrical model of the IM as well as the mechanical load. Taking into account that using BG it is possible to acquire a model of both domains, many efforts were made to represent the electrical dynamics of the IM using this formalism [21], [22].

Two novel approaches are included in the model respect to those developed in current literature:

1) Stator resistances are represented as a series of twelve modulated resistive sources "RS" in the $a b c$ frame.

2) Modulated gyrators "MGY" are used to represent the virtual voltage sources included when the electric variables are refered in the $d q 0$ frame [23].

Fig. 2.a shows these ideas in the standard formalism used to represent electric circuits while Fig. 2.b shows the equivalent model in BG. Here $\mathbf{K}$ and $\mathbf{K}^{\mathbf{T}}$ are the matrices that represent the power invariant transformation from $a b c$ to $d q 0$ and from $d q 0$ to $a b c$, respectively [12].

The approach proposed in 1) is useful for modeling the spatial distribution of the stator winding resistances. The primary bond of the "RS" belongs to the electric domain while the secondary bond lies in the thermal domain. This concept is explained in detail along next section. It is important to bear in mind that in the $d q 0$ "side" these three resistances $\left(R_{a}, R_{b}\right.$ and $R_{c}$ ) are seen as the two statoric resistances used in the standard IM model (in $d q 0$ variables).

The approach in 2) illustrates in a more comprehensible manner the power conservation. This is derived from [23] but here it was extended in order to adapt this idea to the model that considers IL. Next, the analysis of the two virtual voltage sources in the left side of Fig. 1 is performed. The subscript $d$ is used for the upper bond of the "MGY" and $q$ is used for the lower one (Fig. 2.b).

The relationship in the MGY indicates that:

$$
\begin{aligned}
& e_{d}=\omega L_{l s} f_{q} \\
& e_{q}=\omega L_{l s} f_{d}
\end{aligned}
$$

where the generalized flows and efforts are indicated with $f$ and $e$, respectively. Substituting $f_{d}$ by $i_{d s 1}$ and $f_{q}$ by $i_{q s 1}$ in (5) it can be seen that the power absorbed by the lower virtual voltage source is the same that the one delivered by the upper source. i.e. the power delivered/absorved by each one of this sources varies with the selected reference frame but the addition remains always equal to zero.

This analysis can be extended to the rest of the virtual sources. Hence, it is graphically proved what is stated in [24]. This is:

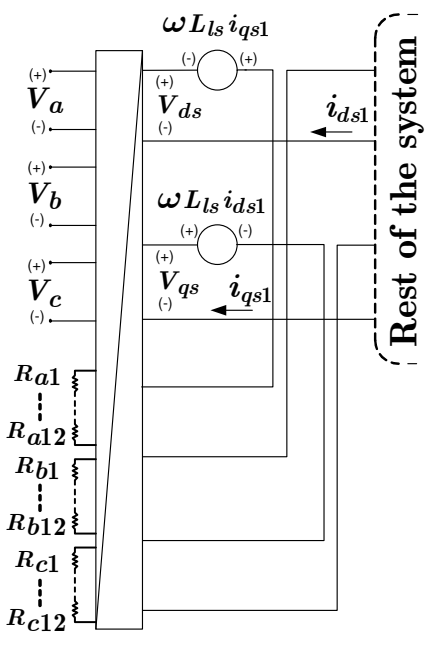

(a)

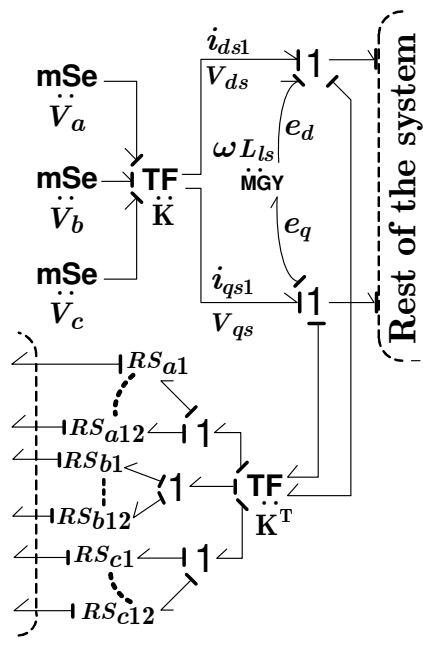

(b)
Fig. 2. (a) Standard electric circuit, (b) equivalent circuit in BG. 


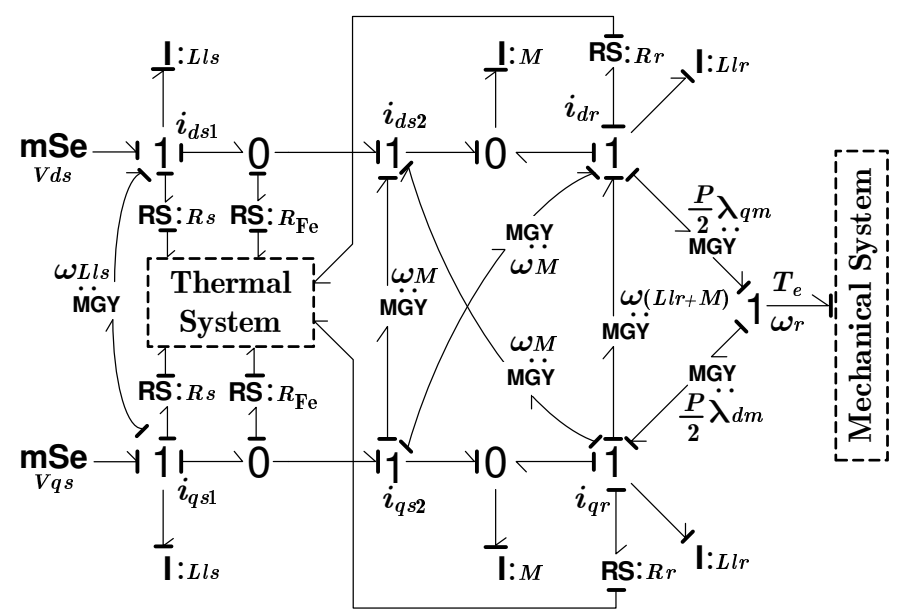

Fig. 3. BG representation of the IM in $q d 0$ variables.

"The total power delivered/absorbed by virtual voltage sources is always zero independently of the selected reference frame".

The complete model in BG is shown in Fig. 3 where all the virtual voltage sources are represented by "MGY". Considering that, the power dissipated by the $R_{F e}$ and $R_{r}$ is absorbed by the thermal sub-system, the secondary bonds of those RS's enter the thermal sub-system. The voltage sources $v_{d r}$ and $v_{q r}$ in Fig. 1 are zero because it is a squirrel cage rotor. The rest of the electrical components modeled in $\mathrm{BG}$ also appear in Fig. 3. Here the energetic interaction with the mechanical load is performed with two MGY [22].

\section{THERMAL MODEL}

The thermal model considers stator teeth and slots as independent elements (see $\mathrm{E}_{3}$ and $\mathrm{E}_{4}$ in Fig. 4). To keep consistency, the external part of the stator yoke is divided into two elements $\left(E_{1}\right.$ and $\left.E_{2}\right)$. This array of four elements is repeated 36 times which is the number of stator teeth/slots.

Next, the criterion adopted to model the thermal behavior is summarized:

- External elements $\left(\mathrm{E}_{1}\right.$ and $\left.\mathrm{E}_{2}\right)$ interchange heat between them and with internal elements $\left(\mathrm{E}_{3}\right.$ and $\left.\mathrm{E}_{4}\right)$ by conduction and dissipate heat to the environment.

- Internal elements interchange heat between them and with external elements by conduction and interact with the rotor through the air-gap.

- The rotor receives the heat dissipated in the rotor resistances, interacts with all the internal elements (through the air-gap) and dissipates heat to the ambient.

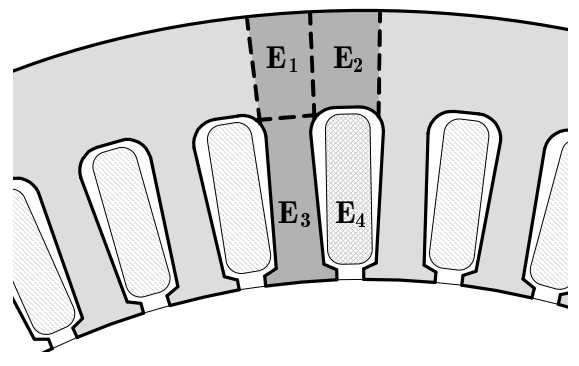

Fig. 4. Division of elements in the stator.

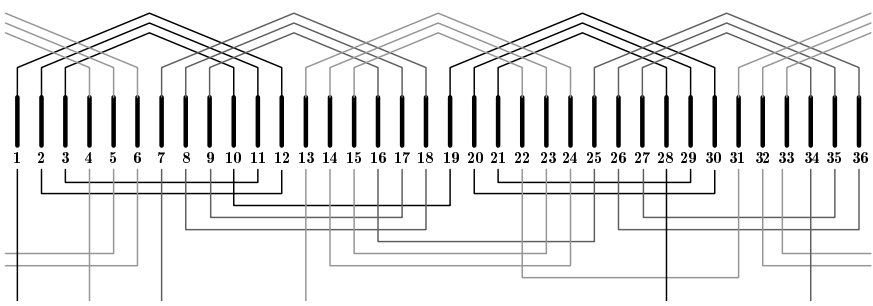

Fig. 5. Spatial distribution of stator windings in the stator slots.

- The iron of the stator $\left(\mathrm{E}_{1}, \mathrm{E}_{2}\right.$ and $\left.\mathrm{E}_{3}\right)$ receives the heat dissipated in both $R_{F e}$ that is distributed proportionally to the element's area.

- The 36 slots receive the heat dissipated by the 36 stator resistances (placed in the $a b c$ frame). The slot where each resistance is placed depends on the way the stator winding is performed (see Fig. 5).

- Thermal radiation is neglected.

\section{A. Conduction Between Elements}

Each of this elements has independent temperature. As consequence of the temperature difference with its neighbor, it interchanges heat by conduction according to the experimental Fourier law:

$$
\frac{\partial Q}{\partial t}=-\frac{A}{\rho} \frac{\partial T}{\partial x}
$$

the heat transfer takes place through the cross-sectional area $A ; \rho$ is the thermal resistivity between the elements. $\partial T / \partial x$ is the spatial temperature gradient. In this case:

$$
\frac{\partial T}{\partial x}=\frac{\Delta T}{\Delta x}=\frac{\left(t_{i}-t_{j}\right)}{\Delta x}
$$

where $t_{i, j}$ is the temperature of element $i, j$ and $\Delta x$ is the distance between the centre of elements.

\section{B. Air-Gap Representation}

Given the high relative speed in the air-gap it was proved experimentally in [25] that heat transfer by conduction and convection between rotor and stator can be modeled considering the air-gap as a thermal resistance. By assuming a value approximately ten times the resistivity between elements, both phenomena are included.

\section{Dissipation Toward the Ambient}

Under the same hypothesis assumed to model the air-gap, it is possible to model the dissipation toward the ambient as a modulated thermal resistance. The resistivity is function of the ventilation. For the case under study, IMs does not have forced ventilation. Therefore two possible scenarios exist:

- IMs are exposed to the exterior $\rightarrow$ ventilation is function of the vehicle's velocity.

- IMs are confined $\rightarrow$ thermal resistance is constant.

The element's temperature on the other side of the thermal resistance is the ambient temperature $t_{a m b}$. 


\section{Heat Storage}

Based on the first law of thermodynamics and assuming that neither phase change nor net work occur in the element:

$$
Q=\gamma \Delta T
$$

where $Q$ is the absorbed heat, $\gamma$ is the heat capacity and $\Delta T$ is the temperature variation produced in the element.

All the sources of entropy plus the incoming/outgoing entropy via conduction conform the total flow of entropy $(\dot{S})$. The rate of heat flow $(\partial Q / \partial t)$ is obtained by multiplying the total flow of entropy and element temperature. Hence, (8) can be re-written in differential form as:

$$
\dot{S}=\frac{d}{d t} S=\frac{\gamma}{T} \frac{d}{d t} T
$$

Eq. (9) is useful to determine the evolution of the element's temperature when the total flow of entropy and element's initial temperature are known.

\section{E. Thermal Model in $B G$}

The complete thermal behavior previously described can be modeled in BG (see Fig. 6) using a source of effort to fix $t_{a m b}$ and three types of BG elements. Here the bondgraphic generalized effort $(e)$ represents temperature $(T)$ and the flow $(f)$ is the flow of entropy $(\dot{S})$.

- Thermal conductivity is represented with a thermal resistance " $\mathbf{R}_{\mathbf{t h}}$ " whose relationship between primary and secondary bonds is given by:

$$
\begin{aligned}
f_{1} e_{1} & =\frac{1}{\theta}\left(e_{1}-e_{2}\right) \\
f_{2} e_{2} & =f_{1} e_{1}
\end{aligned}
$$

where the product $f_{1} e_{1}$ is the rate of heat flow $(\partial Q / \partial t)$. Replacing $\theta=\rho \Delta x / A$ (thermal resistance), (10) becomes equivalent to (6). To model the effect of ventilation in the dissipation toward the ambient $\theta$ varies as [26]:

$$
\theta=\theta_{0}\left(1-\beta V_{x}\right)
$$

where $\beta$ represents the reduction in the thermal resistance.

Eq. (11) states that the outgoing heat from an element is totally transferred to the other.

- The incoming heat by dissipation on electric resistances is modeled with a modulated resistive source "RS". Relationship between primary and secondary bonds is given by:

$$
\begin{array}{r}
e_{1}=R f_{1} \\
f_{2}=f_{1} e_{1} / e_{2}
\end{array}
$$

Primary bond (indicated with subscript 1) belongs to the electric domain and has free causality. Secondary bond (subscript 2) enters the thermal model as a source of entropy. For stator resistance, $R$ is modulated as function of the temperature in the slot where it is placed. Rotor electric resistances varies according to the rotor temperature $\left(t_{r o t}\right)$. The dependence is given by:

$$
R=R_{20}\left[1+\alpha\left(t_{i}-20\right)\right]
$$

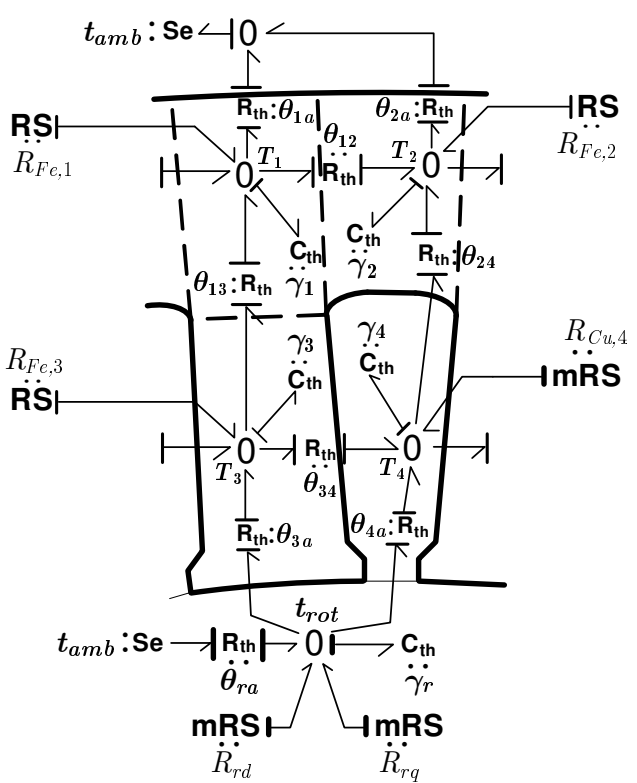

Fig. 6. BG representation of the thermal model.

$R_{20}$ is the resistance value at $20^{\circ} \mathrm{C}, t_{i}$ is the element's temperature in $\left[{ }^{\circ} \mathrm{C}\right]$ and $\alpha$ is the temperature coefficient.

- Heat storage is represented with a thermal capacity $\mathbf{C}_{\text {th }}$. It inherits the relationship from a capacitor $(C \dot{e}=f)$ but in this case the value of the capacity is inversely proportional to element temperature (i.e. $C=\gamma / e$ ). With this substitution, the relationship becomes equivalent to (9).

The thermal model in BG is finally presented in Fig. 6. Here subscripts $1,2,3,4$ and $a$ used in parameters refer to $\mathrm{E}_{1,2,3,4}$ and ambient respectively.

\section{Mechanical Model}

The mechanical model is in correspondence with the prototype under construction by the Applied Electronic Group at the National University of Río Cuarto. The geometry in Fig. 7 responds to the so-called neighborhood electric vehicle.

The model used in this work does not consider lateral dynamics. Due to the symmetry between left and right side, it is simplified into a half vehicle model with only two wheels (frontal and rear). Given that the vehicle has rear traction, the motor is coupled only to the rear wheel. The rotational dynamics of the rear wheel is given by:

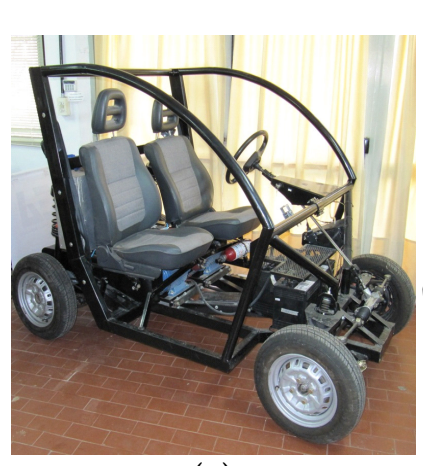

(a)

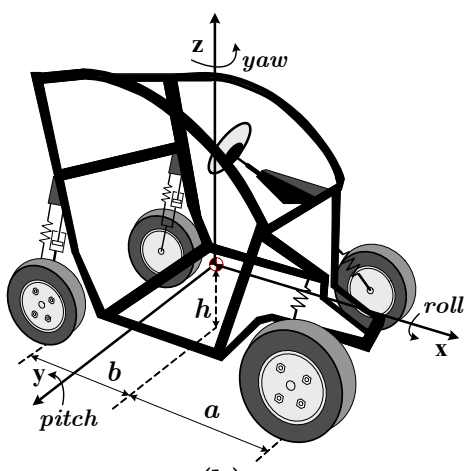

(b)
Fig. 7. (a) Vehicle prototype, (b) vehicle geometry. 


$$
I_{W} \dot{\omega}_{W}=T_{e} N-F_{r} r_{W}-B_{W} \omega_{W}
$$

where $I_{W}, \omega_{W}, r_{W}$ and $B_{W}$ are the moment of inertia, velocity, radius and rotational friction coefficient of the wheel, respectively. $N$ is the fixed gear ratio that relates the motor with the wheel. $F_{r}$ is the longitudinal force on the patch contact. The dynamics involved in frontal wheel is the same except that $T_{e}=0$.

The longitudinal dynamics receives the forces produced on the patch contact of rear and frontal wheel $\left(F_{r}\right.$ and $\left.F_{f}\right)$ and determines de velocity $\left(V_{x}\right)$. The aerodynamic drag force $F_{\text {drag }}$ is function of $V_{x}$ and tends to stop the vehicle. For longitudinal dynamics of half vehicle, the set of equations is:

$$
\begin{gathered}
F_{r}+F_{f}-F_{\text {drag }}=\left(m_{\text {tot }} / 2\right) \dot{V}_{x} \\
F_{\text {drag }}=\frac{1}{2} C_{X}\left(A_{f} / 2\right) \rho_{a} V_{x}^{2}
\end{gathered}
$$

where $m_{t o t}$ and $A_{f}$ are the total mass and frontal area of the vehicle, respectively. $C_{X}$ is the aerodynamic coefficient and $\rho_{a}$ is the air density.

The physical principles and modeling with BG of the wheel rotational dynamics as well as longitudinal dynamics of the vehicle is presented and discussed in detail in [27].

\section{COMPlete Model}

The model displayed in Fig. 3 represents the electric dynamics and manifests the interaction with the thermal and mechanical domains. In order to obtain the complete model, blocks named "Thermal System" and "Mechanical System" in Fig. 3 are simply replaced by their corresponding BG models. This integrated model gives rise to the Multi-Domain model. Fig. 8 shows the interaction considered and modeled between Electric - Thermal - Mechanical domains. Due to the bidirectional influence between Electric - Mechanical domains and Electric - Thermal domains, the ability of this model to simulate the three domains simultaneously becomes essential.

The energetic interaction between electrical and mechanical parts is performed via two MGY (see Section III-B).

To couple the thermal and electrical sub-systems both $R_{S}$ (from the $d q 0$ ) are transformed to the $a b c$ frame. Each $a b c$ stator resistance is divided into a series of twelve modulated "RS" (see Fig. 2.b) whose secondary bond enters the thermal system in the corresponding slot. Also, each $R_{F e}$ is divided into a series of equivalent "RS" elements. Their secondary side enters the thermal domain in the stator iron elements and the value of $R$ is proportional to the element area. Both $R_{r}$ are modulated "RS" with the secondary bond entering the rotor thermal model that is considered as a lumped mass.

Finally $V_{x}$ is fed back to the thermal system to modulate the ventilation, according to eq. (12). $V_{x}$ is also used to close the speed control loop that compares $V_{x}$ with the velocity profile to be performed. Based on this error the IM torque is imposed using the FOC. Details of the FOC strategy are considered beyond the scope of this work.

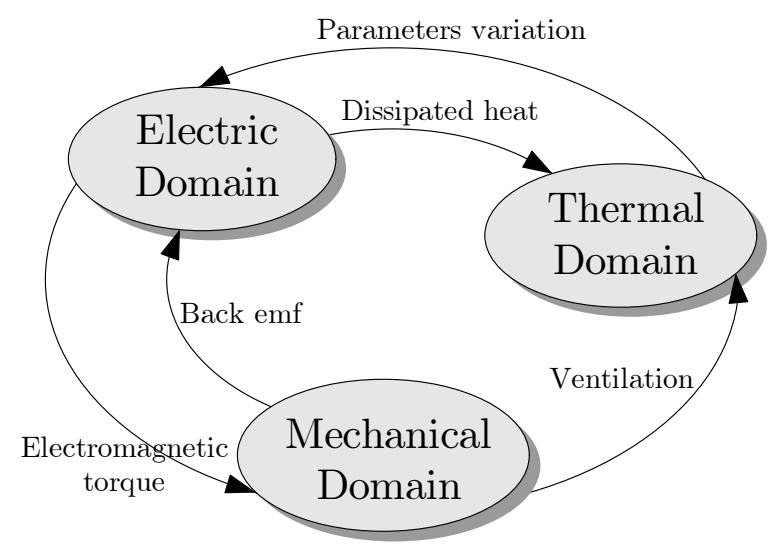

Fig. 8. Interaction between domains.

\section{Simulation And Experimental RESUlts}

The aim of this section is to remark the multidisciplinary feature of the proposed Multi-Domain model. Along the proposed experiments, the evolution of electrical, mechanical and thermal variables are provided. The outstanding point is that the variables are shown under faulty and non-faulty conditions. The parameters value used to perform the numerical simulation are displayed in Table I.

TABLE I

COMPLETE SYSTEM PARAMETERS

\begin{tabular}{|l|c|c|}
\hline \multicolumn{3}{|c|}{ Electrical Domain (rated) } \\
\hline Power $\left(P_{n}\right)$ & 3 & {$[\mathrm{~kW}]$} \\
\hline Line Voltage $\left(V_{n}\right)$ & 28 & {$[\mathrm{~V}]$} \\
\hline Current $\left(I_{n}\right)$ & 81.56 & {$[\mathrm{~A}]$} \\
\hline Frequency $\left(f_{n}\right)$ & 50 & {$[\mathrm{~Hz}]$} \\
\hline Torque $\left(T_{e}\right)$ & 19.4 & {$[\mathrm{Nm}]$} \\
\hline Poles $(P)$ & 4 & \\
\hline$R_{a}=R_{b}=R_{c}$ & 22.476 & {$[\mathrm{~m} \Omega]$} \\
\hline$R_{r}$ & 157 & {$[\mathrm{~m} \Omega]$} \\
\hline$R_{F e}[\Omega]$ \\
\hline$L_{l s}=L_{l r}$ & 89.03 & {$[\mu \mathrm{H}]$} \\
\hline$M$ & 1.21 & {$[\mathrm{mH}]$} \\
\hline \hline \multicolumn{3}{|c|}{ Thermal Domain } \\
\hline Rotor Heat Capacity $\left(\gamma_{r}\right)$ & 1480 & {$\left[\mathrm{~J} /{ }^{\circ} \mathrm{C}\right]$} \\
\hline Element 1 Heat Capacity $\left(\gamma_{1}\right)$ & 105.7 & {$\left[\mathrm{~J} /{ }^{\circ} \mathrm{C}\right]$} \\
\hline Element 2 Heat Capacity $\left(\gamma_{2}\right)$ & 71.1 & {$\left[\mathrm{~J} /{ }^{\circ} \mathrm{C}\right]$} \\
\hline Element 3 Heat Capacity $\left(\gamma_{3}\right)$ & 178.8 & {$\left[\mathrm{~J} /{ }^{\circ} \mathrm{C}\right]$} \\
\hline Element 4 Heat Capacity $\left(\gamma_{4}\right)$ & 43.8 & {$\left[\mathrm{~J} /{ }^{\circ} \mathrm{C}\right]$} \\
\hline Thermal Resistance $\theta_{12}$ & 0.140 & {$\left[{ }^{\circ} \mathrm{C} / \mathrm{W}\right]$} \\
\hline Thermal Resistance $\theta_{13}$ & 0.097 & {$\left[{ }^{\circ} \mathrm{C} / \mathrm{W}\right]$} \\
\hline Thermal Resistance $\theta_{24}$ & 0.464 & {$\left[{ }^{\circ} \mathrm{C} / \mathrm{W}\right]$} \\
\hline Thermal Resistance $\theta_{34}$ & 0.232 & {$\left[{ }^{\circ} \mathrm{C} / \mathrm{W}\right]$} \\
\hline Thermal Resistance $\theta_{3 r}$ & 0.521 & {$\left[{ }^{\circ} \mathrm{C} / \mathrm{W}\right]$} \\
\hline Thermal Resistance $\theta_{4 r}$ & 0.975 & {$\left[{ }^{\circ} \mathrm{C} / \mathrm{W}\right]$} \\
\hline Thermal Resistance $\theta_{r a}$ & 1.115 & {$\left[{ }^{\circ} \mathrm{C} / \mathrm{W}\right]$} \\
\hline Rated Thermal Resistance $\theta_{1 a, 0}$ & 5.188 & {$\left[{ }^{\circ} \mathrm{C} / \mathrm{W}\right]$} \\
\hline Rated Thermal Resistance $\theta_{2 a, 0}$ & 9.980 & {$\left[{ }^{\circ} \mathrm{C} / \mathrm{W}\right]$} \\
\hline Resistance Reduction Coeff. $(\beta)$ & 0.0376 & {$[\mathrm{~s} / \mathrm{m}]$} \\
\hline Temperarute Coeff. $\left(\alpha_{r}=\alpha_{s}\right)$ & 0.00393 & {$\left[{ }^{\circ} \mathrm{C}^{-1}\right]$} \\
\hline Ambient Teperature & 25 & {$\left[{ }^{\circ} \mathrm{C}\right]$} \\
\hline \hline \multicolumn{3}{|c|}{ Main } \\
\hline Wheel Inertia $\left(I_{W}\right)$ & 1.95 & {$\left[\mathrm{kgm}{ }^{2}\right]$} \\
\hline Wheel Radius $\left(r_{W}\right)$ & 0.268 & {$[\mathrm{~m}]$} \\
\hline Rotational Friction Coeff. $\left(B_{W}\right)$ & 0.023 & {$[\mathrm{Nms}]$} \\
\hline Fixed Gear Ratio $(N)$ & 3 & \\
\hline Vehicle Total Mass $\left(m_{t o t}\right)$ & 640 & {$[\mathrm{~kg}]$} \\
\hline Vehicle Frontal Area $\left(A_{f}\right)$ & 1.4 & {$\left[\mathrm{~m}^{2}\right]$} \\
\hline Aerodynamic Coeff. $\left(C_{X}\right)$ & 0.5 & \\
\hline Air Density $\left(\rho_{a}\right)$ & 1.225 & {$\left[\frac{\mathrm{kg}}{\mathrm{m}^{3}}\right]$} \\
\hline \multicolumn{2}{|c|}{ ) } \\
\hline
\end{tabular}



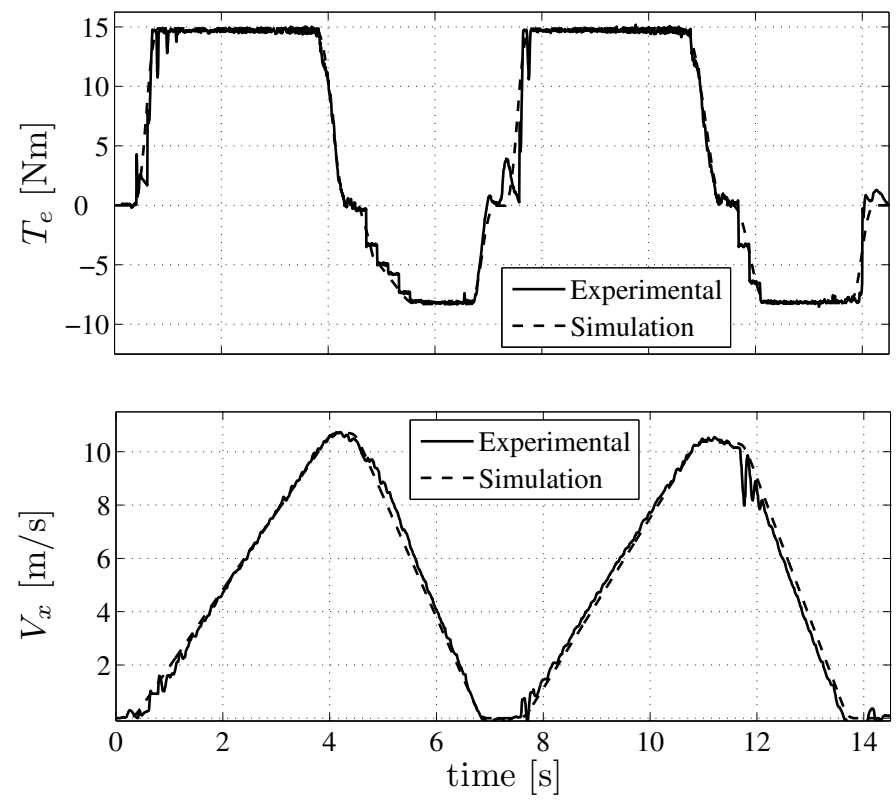

Fig. 9. (a) Electromagnetic torque, (b) $V_{x}$.

As a first part of this section acceleration-brake maneuver of the vehicle was carried on with the objective of evaluating and validating the electromechanical interaction. Fig. 9 shows simulation and experimental results for the vehicle velocity and the electromagnetic torque of the traction. The vehicle is conducted from rest to the maximum speed during $t=0.5[\mathrm{~s}]$ to $t=4$ [s] and then back to rest, during $t=4$ [s] to $t=7$ [s]. This maneuver is performed twice. From this figure, it is possible to assert that in the period $t=4-7$ [s] a regenerative braking occur. This statement is validated through the electric power consumed by IM, depicted in Fig. 10. This power is positive for traction operation, while the negative value during brake, manifests the regenerative braking capability. The high correlation between experimental (solid line) and simulation (dash line) results obtained in the aforementioned figures, allows using the proposed model to obtain a correct prediction of the total energy consumed for any predefined drive cycle.

As a second part of this section, a set of experiments were performed with the objective of highlighting the interaction between the different domains of the proposed model. To this end, the vehicle was maneuvered in a straight line motion with velocity profile determined by SAE J227a Schedule C

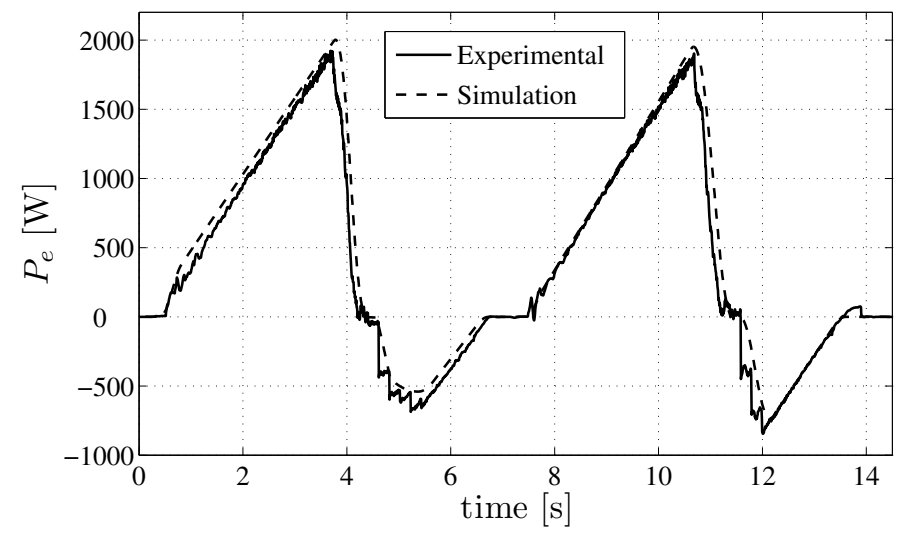

Fig. 10. Electric power during maneuver.

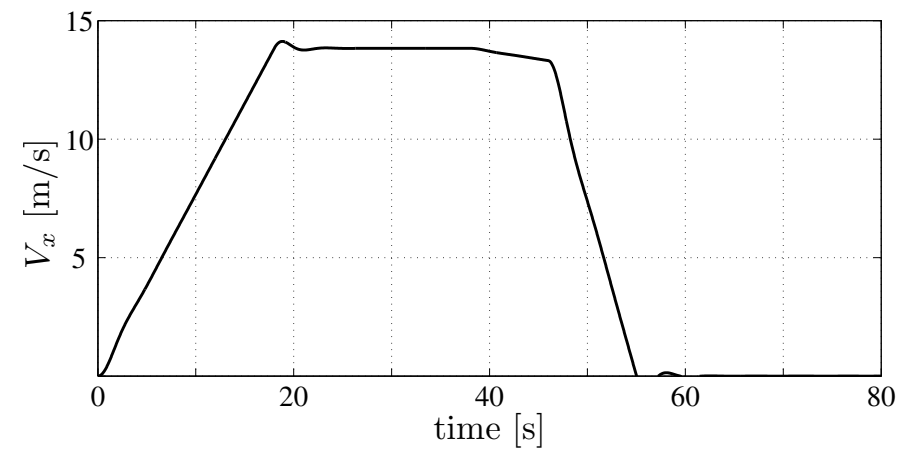

Fig. 11. $V_{x}$ profile.

drive cycle. The cycle was repeated 75 times, Fig. 11 shows $V_{x}$ during two complete cycles.

The interaction between the mechanical and thermal domain was evidenced by taking into account the ventilation of the IM (see Fig. 8) in order to show how it impacts on the IM temperature. Fig. 12 shows the evolution of the temperature in three different parts of the IM with and without ventilation during the experiment. The three elements are: the rotor, the element 1 of the copper and the element 19 of the iron, in the figure "Rotor", "Cu 1" and "Fe 19", respectively. The figure shows a significant increase in temperature if the IM is not properly ventilated. This issue must be considered during design stage of the IM ventilation.

The impact of the temperature increase on IM parameters (interaction between thermal and electric domain, see Fig. 8) is revealed in Fig. 13. It shows the evolution of the stator and rotor resistances for three different scenarios. Solid line shows their value without considering the thermal dependence. This constant value is obtained by the IM tests (DC, no-load and load tests) and is used to design the FOC. However, in order to analyze a more realistic situation, the thermal dependence is considered for ventilated (dashed line) and non-ventilated (dotted line) conditions. Deviation of the resistances are between $10 \%$ and $20 \%$ for these scenarios. This variation has a negative impact on the dynamic response of the FOC. Therefore, with the proposed multi-domain model it is possible to assess influence of parameter detuning on the performace of different control strategies. The on-line resistance estimation proved to improve significantly the controller performance [28].

Finally the impact and the interaction between domains for an IM winding fault is analyzed. As in the previous experiment, the velocity profile $\mathbf{S A E} \mathbf{J 2 2 7}$ a Schedule $\mathbf{C}$ was

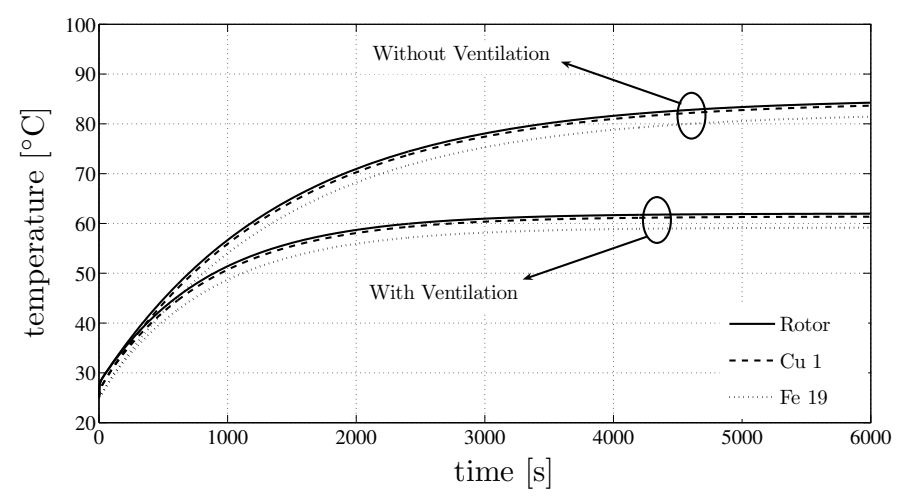

Fig. 12. Temperature evolution with/without ventilation. 

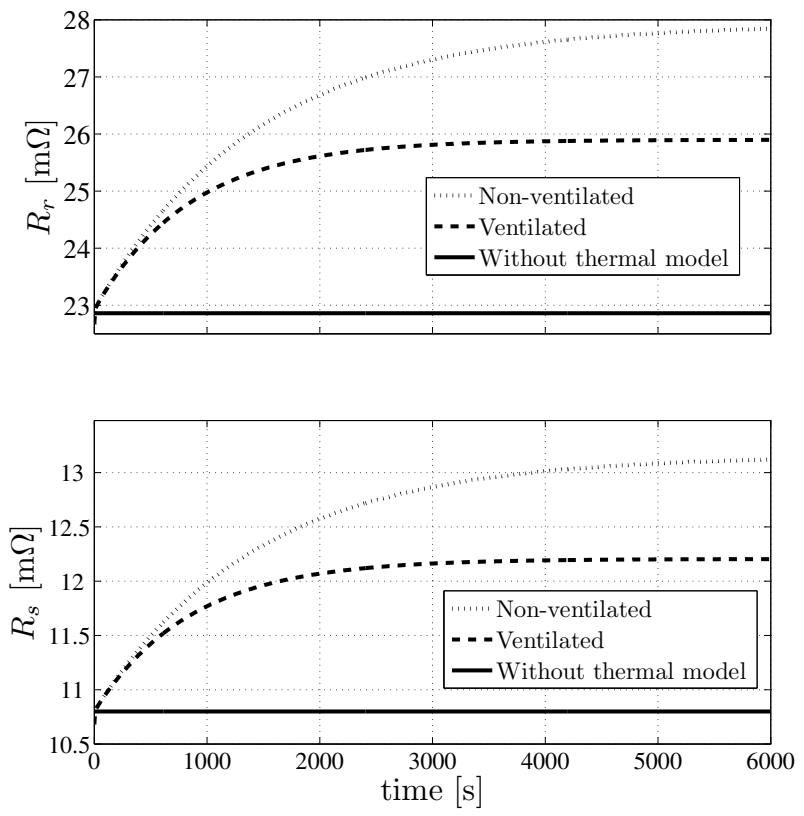

Fig. 13. (a) $R_{r}$ evolution, (b) $R_{s}$ evolution.

used and repeated 75 times. In the first part of the experiment, until $t=3000$ [s], the IM was in non faulty condition. From $t=3000[\mathrm{~s}]$ a stator winding fault in phase "a" is simulated. It was created by duplicating the value of $R_{a}$. The complete additional resistance is located in the $1^{\text {st }}$ slot. In this faulty condition, the maneuver is repeated until the end of the experiment. Fig. 14.a shows $V_{x}$ during two complete cycles. The first cycle is without fault and the second is performed immediately after the fault occurs. Both profiles are almost equal. This is because the FOC resulted tolerant to that fault, nonetheless the power dissipated by stator resistances increases considerably (see Fig. 14.b). Also, this figure shows oscillation in the IM power due to the fault, in the second cycle. This oscillation at twice of the supply frequency is a well known effect when a stator asymmetry appears [29].

Fig. 15 shows the temperature evolution of the rotor, the slot where the fault occurs ( $\mathrm{Cu} 1)$ and the external iron opposed to $\mathrm{Cu} 1$ (named $\mathrm{Fe}$ 19). In absence of fault, the motor operates in the range of admissible temperatures. Due to the increment in power during the fault, the motor is heated. The most critical part is the slot where the resistance increment took place.

Owing to the thermal model characteristics not only the evolution of the temperature is possible to obtain and analyze, but also the spatial distribution in the IM can be acquired, as shown in Fig. 16. This figure represent the thermal distribution of the previous experiment, where an IM winding fault was simulated. The figure shows an important thermal gradient in the $1^{\text {st }}$ slot, where the fault is located.

The results obtained in this section manifest the capability of the proposed multi-domain model to predict the simultaneous interaction between domains for different EV conditions, being a helpful tool during design stage and/or for evaluating different faulty conditions.
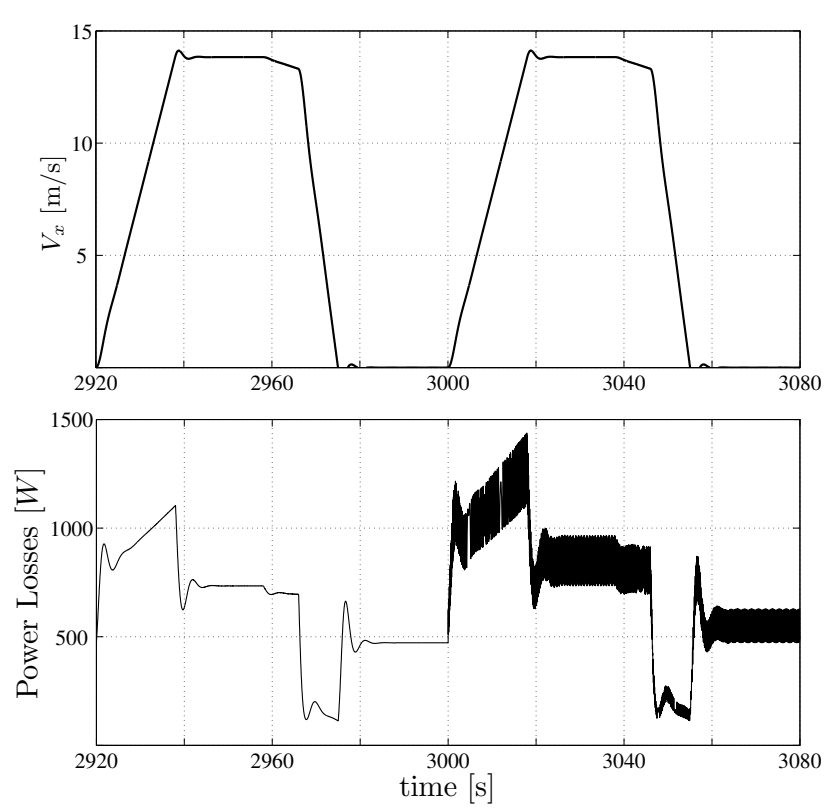

Fig. 14. (a) $V_{x}$ profile, (b) Power Losses without/with failure.

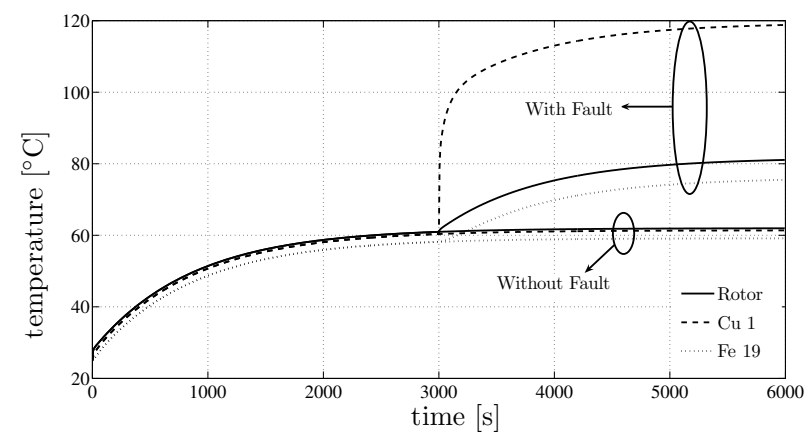

Fig. 15. Temperature evolution with/without fault.

\section{CONCLUSION}

A Multi-Domain model of an electric vehicle was developed and tested. The model includes the electric, thermal and mechanical domains and their interaction, using Bond Graph. The electric model can be easily set to include stator faults and its influence in the whole system can be analyzed.

The presented model is a helpful tool in the design stage. It allows evaluating the vehicle and traction drive performance in different working conditions such as: driving cycles, faults in the stator winding, ventilation, etc. A benefit of the proposed model is to perform a fine tune of the control system taking into account the parameters variation due to temperature.

In the type of applications tackled in the present work, fault tolerant control strategies are widely used [30], [31]. When this strategies needs to be developed and evaluated, the proposed model becomes a helpful tool.

Experimental results validate the electro-mechanical interaction. Future work will be focused on the validation of the thermal model and the interaction with the rest of the system.

\section{ACKNOWLEDGMENT}

This work was supported by Universidad Nacional de Río Cuarto (UNRC), FONCyT-ANPCyT and CONICET. 


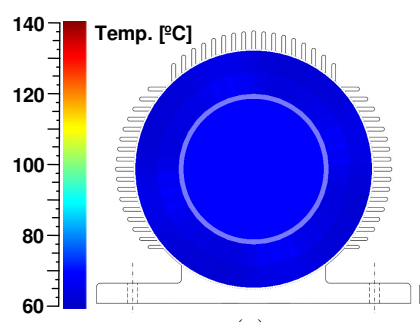

(a)

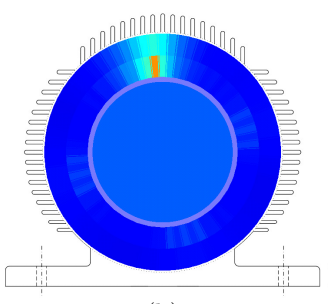

(b)

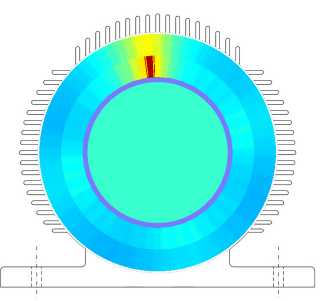

(c)

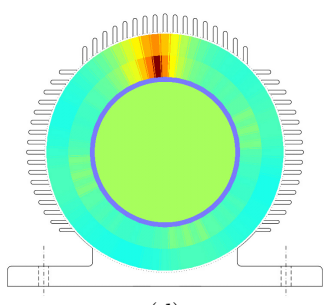

(d)

Fig. 16. Temperature distribution. (a) Before the fault. (b) 100 [s] after fault. (c) 1500 [s] after fault. (d) 3000 [s] after fault.

\section{REFERENCES}

[1] C. Chan, A. Bouscayrol, and K. Chen, "Electric, hybrid, and fuelcell vehicles: Architectures and modeling," IEEE Trans. Veh. Technol., Vol. 59, No. 2, pp. 589-598, Feb. 2010.

[2] K. Ohyama, M. Nashed, K. Aso, H. Fujii, and H. Uehara, "Design using finite element analysis of a switched reluctance motor for electric vehicle," Journal of Power Electronics, Vol. 6, No. 2, pp. 163-171, Apr. 2006.

[3] S. Leva, A. Morando, and P. Colombaioni, "Dynamic analysis of a highspeed train," IEEE Trans. Veh. Technol., Vol. 57, No. 1, pp. 107-119, Jan. 2008.

[4] F. Roy, B. Dutoit, F. Grilli, and F. Sirois, "Magneto-thermal modeling of second-generation hts for resistive fault current limiter design purposes," IEEE Trans. Appl. Supercond., Vol. 18, No. 1, pp. 29-35, Mar. 2008.

[5] S. Onoda and A. Emadi, "PSIM-based modeling of automotive power systems: conventional, electric, and hybrid electric vehicles," IEEE Trans. Veh. Technol., Vol. 53, No. 2, pp. 390-400, Mar. 2004.

[6] R. Krishnan, Electric Motor Drives: Modeling, Analysis and Control, Prentice Hall, 2001.

[7] P. Voigt and G. Wachutka, "Electro-fluidic microsystem modeling based on kirchhoffian network theory," in International Conference on Solid State Sensors and Actuators, Vol. 2, pp. 1019-1022, Jun. 1997.

[8] F. E. Cellier, Continuous System Modeling, New York: Springer Verlag, 1991.

[9] D. C. Karnopp, D. L. Margolis, and R. C. Rosenberg, System Dynamics: Modeling And Simulation of Mechatronic Systems, New York, USA: Willey InterCiences, 2000.

[10] A. Reibiger and H. Loose, "Bond graphs and matroids," Mathematics and Computers in Simulation, Vol. 53, No. 4-6, pp. 323-332, Oct. 2000.

[11] L. Silva, P. de la Barrera, C. De Angelo, G. Bossio, and G. Garcia, "Multi-domain modeling of electric traction drives using bond graphs: Application to fault diagnosis," in Industrial Electronics, IECON '09, 35th Annual Conference of IEEE, pp. 3455-3460, 2009.

[12] P. C. Krause, O. Wasynczuk, and S. D. Sudhoff, Analysis of Electric Machinery, New York, USA: IEEE Press, 1994.

[13] A. Lamine and E. Levi, "Dynamic induction machine modelling considering the stray load losses," in 39th International Universities Power Engineering Conference, Vol. 1, pp. 582-586, Sep. 2004.

[14] R. M. Tallam, T. G. Habetler, and R. G. Harley, "Transient model for induction machines with stator winding turn faults," IEEE Trans. Ind. Appl., Vol. 38, No. 3, pp. 632-637, May/Jun. 2002.

[15] A. Bellini, C. Concari, G. Franceschini, E. Lorenzani, C. Tassoni, and A. Toscani, "Thorough understanding and experimental validation of current sideband components in induction machines rotor monitoring," in IEEE Industrial Electronics, IECON '06, pp. 4957-4962, 2006.

[16] G. O. García, "Controladores eficientes para el accionamiento de motores de inducción,” Ph.D. Tesis, Univ. Fed. de Río de Janeiro (UFRJ), Mar. 1994.

[17] G. O. García, J. C. Mendes Luís, R. M. Stephan, and E. H. Watanabe, "An efficient controller for an adjustable speed induction motor drive," IEEE Trans. Ind. Electron., Vol. 41, No. 5, pp. 533-539, Oct. 1994.

[18] E. Levi, "Impact of iron loss on behavior of vector controlled induction machines," IEEE Trans. Ind. Appl., Vol. 31, No. 6, pp. 1287-1296, Nov./Dec. 1995.

[19] E. Levi, M. Sokola, A. Boglietti, and M. Pastorelli, "Iron loss in rotorflux-oriented induction machines: identification, assessment of detuning, and compensation," IEEE Trans. Power Electron., Vol. 11, No. 5, pp. 698-709, Sep. 1996.
[20] P. M. de la Barrera, G. R. Bossio, J. A. Solsona, and G. O. García, "On-line iron loss resistance identification by a state observer for rotor-flux-oriented control of induction motor," Energy conversion and management, Vol. 49, No. 10, pp. 2742-2747, Oct. 2008.

[21] S. Junco, "Real and complex power bond graph modeling of the induction motor," in International Conf. on Bond Graph Modeling and Simulation, ICBGM '99, pp. 323-328, 1999.

[22] D. Karnopp, "Understanding induction motor state equations using bond graph," in International Conference on Bond Graph Modeling and Simulation, ICBGM '03, 2003.

[23] A. Donaire, "Análisis y síntesis de sistemas no lineales de control en base a propiedades físicas, estructurales y causales de modelos bond graph," Ph.D. Tesis, Universidad Nacional de Rosario, Mar. 2009.

[24] R. Ortega, C. Canudas, and S. Seleme, "Nonlinear control of induction motors: Torque tracking with unknown load disturbance," IEEE Trans. Autom. Control, Vol. 38, No. 11, pp. 1675-1680, Nov. 1993.

[25] J. Bastos, M. Cabreira, N. Sadowski, S. Arruda, and S. Nau, "A thermal analysis of induction motors using a weak coupled modeling," IEEE Trans. Magn., Vol. 33, No. 2, pp. 1714-1717, Mar. 1997.

[26] D. Staton, A. Boglietti, and A. Cavagnino, "Solving the more difficult aspects of electric motor thermal analysis in small and medium size industrial induction motors," IEEE Trans. Energy Convers., Vol. 20, No. 3, pp. 620-628, Sep. 2005.

[27] L. I. Silva, G. A. Magallán, C. H. De Angelo, and G. O. García, "Vehicle dynamics using multi-bond graphs: Four wheel electric vehicle modeling," in 34th Ann. Conf. IEEE Ind. Electronics Society, IECON '08, pp. 2846-2851, Nov. 2008.

[28] C. Kwon, "An on-line rotor resistance estimator for induction machine drives," Journal of Power Electronics, Vol. 9, No. 3, pp. 354-364, May 2009.

[29] S. F. Legowski, A. H. M. S. Ula, and A. M. Trzynadlowski, "Instantaneous power as a medium for the signature analysis of induction motors," IEEE Trans. Ind. Appl., Vol. 32, No. 4, Jul./Aug. 1996.

[30] Y. Lee and T. G. Habetler, "A stator turn fault tolerant strategy for induction motor drives in safety critical applications," in Power Electronics Specialists Conference, PESC '06. 37th IEEE, pp. 1-7, 2006.

[31] A. M. S. Mendes, X. M. Lopez-Fernandez, and A. J. Marques Cardoso, "Thermal performance of a three-phase induction motor under fault tolerant operating strategies," IEEE Trans. Power Electron., Vol. 23, No. 3, pp. 1537-1544, May 2008.

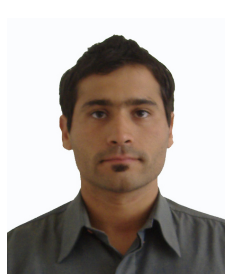

Luis I. Silva was born in Rosario, Argentina, in 1979. Received the Electronic Engineer degree from the Universidad Nacional de Rosario, Argentina, in 2005 and the Master degree in Space Sciences and Technologies from the Lulea Tekniska Universitet, Sweeden in 2007. In 2007, he joined the Grupo de Electrónica Aplicada, Universidad Nacional de Río Cuarto, Argentina, where he is currently a PhD candidate in Engineering Sciences. His research interests are modeling and simulation applied to hybrid electric vehicles.

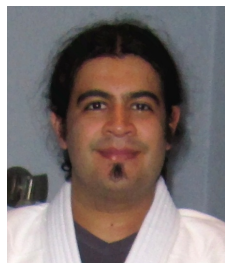

Pablo M. de la Barrera was born in Río Cuarto, Argentina, in 1978. He received the Electrical Engineer and the M.Sc. degrees from Universidad Nacional de Río Cuarto, Argentina, in 2003 and 2006, respectively and the Dr. of Engineering degree from the Universidad Nacional del Sur, Argentina, in 2009. In 1998, he joined the Grupo de Electrónica Aplicada, Universidad Nacional de Río Cuarto. He is also currently with Consejo Nacional de Investigaciones Científicas y 
Técnicas, Argentina. His research interests are in modeling and control of electric machines, fault detection in electric machines and renewable energy conversion.

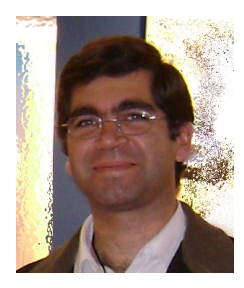

Cristian H. De Angelo was born in Río Cuarto, Argentina, in 1974. He received the Electrical Engineer degree from the Universidad Nacional de Río Cuarto, Argentina, in 1999 and the Dr. of Engineering degree from the Universidad Nacional de La Plata, Argentina, in 2004. Since 1994, he has been with the Grupo de Electrónica Aplicada, Universidad Nacional de Río Cuarto. He is also currently with Consejo Nacional de Investigaciones Científicas y Técnicas, Argentina. His research interests include fault diagnosis on electric machines, sensorless motor control, electric vehicles, and renewable-energy generation.

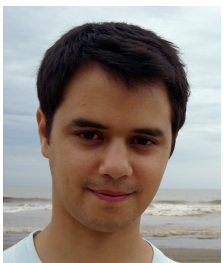

Facundo Aguilera was born in San Luis, Argentina, in 1985. Received the Electronic Engineer degree from the Universidad Nacional de San Luis, Argentina, in 2009. In 2010, he joined the Grupo de Electrónica Aplicada, Universidad Nacional de Río Cuarto, Argentina, where he is currently a PhD candidate in Engineering Sciences. His actual research interests are digital systems, electric vehicles and renewable-energy generation.

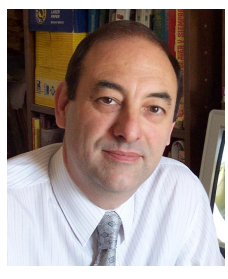

Guillermo O. García was born in Río Cuarto, Argentina, in 1954. Received the Electrical and Electronics Engineering degree from the National University of Córdoba, Argentina, in 1981, the M.Sc. and Dr. in Electrical Engineering from COPPE, Federal University of Río de Janeiro, Brazil, in 1990 and 1994, respectively. Presently is Director of the Grupo de Electrónica Aplicada and professor at the Departamento de Electricidad y Electrónica of the Universidad Nacional de Río Cuarto. He is also member of the Consejo Nacional de Investigaciones Científicas y Técnicas, Argentina. His research interests are in power electronics, motion control, electric and hybrid vehicles, renewable energy conversion and electric wind power generation, fault diagnosis in electric drives and industrial automation and control. 